\title{
USE OF THE MONTI PRINCIPLE FOR CONSTRUCTING A CONTINENT GASTROSTOMY
}

\author{
LUIZ A. P. ARAUJO, CARLOS T. BRANDT, SALVADOR V. C. LIMA, FABIO O. VILAR, \\ ANDRE A. P. ARAUJO \\ Divisions of Pediatric Surgery and Urology, Center of Experimental Surgery, Federal University of \\ Pernambuco, Recife, Pernambuco, Brazil
}

\begin{abstract}
Objective: To research technical alternatives for permanent gastrostomy that minimizes the drawbacks and complications reported by several authors.

Materials and Methods: An experimental model was developed where the material was divided into 2 groups: the study group (SG) composed of 12 half-breed dogs where the proposed technique was applied, and the control group (CG) composed of 10 animals where a gastrostomy as proposed by Webster in 1974 was applied. On the 90th postoperative day, both groups underwent tests for assessing competence concerning leakage. These were performed under general anesthesia and following sacrifice.

Results: In the SG, under anesthesia only one animal had leakage through the gastrostomy. Following sacrifice, leakage was observed in 2 animals. In the CG, under anesthesia, 2 animals had leakage and, following sacrifice, only 1 animal did not present leakage. On histopathological analysis of the SG, gastric mucosa was evidenced around the jejunal tubes, with normal features, moderate inflammatory mononuclear infiltrate in jejunal tubes and only slight infiltrate around the gastrostomy stoma. In the CG, ulceration was constant around the external stoma of the gastrostomy tubes. In the corium, the inflammatory infiltrate was less intense than in the SG. The SG proved to be more efficacious than the CG concerning leakage, and this efficacy is attributed to the submucous valvular system.

Conclusions: The featured technique showed competence concerning leakage, allowing its clinical applicability as an alternative for permanent gastrostomy.
\end{abstract}

Key words: urinary diversion; urinary reservoirs, continent; experiments

Int Braz J Urol. 2005; 31: 62-68

\section{INTRODUCTION}

The research for a gastrostomy, which can address the inability of using the oral route for feeding, either in neurological diseases or neoplasms of oropharynx, esophagus and stomach, has been reported since the 19th century (1). The importance of gastrostomy as a therapeutic option to enable the temporary or permanent nutrition of several patients is uncontested. However, many drawbacks and complications are attributed to these procedures, such as obstruction of the duodena by the catheter balloon, stomach prolapse caused by the gastrostomy, persistency of gastrocutaneous fistula, dehiscence of the gastrostomy's external stoma with peritonitis and sepsis. Such events have led many authors to develop various techniques in an effort to solve or minimize these problems (2-4). 
In an effort to contribute to the enhancement of current gastrostomy techniques, especially permanent ones, a new technique based on the Monti principle was conceived. This uses a segment of the small bowel for fashioning a continent vesicostomy (5). Similarly, applying a jejunal segment to the stomach was proposed, aiming to obtain a continent gastrostomy offering less drawbacks than the current ones.

\section{MATERIALS AND METHODS}

The study was conducted on 22 half-breed dogs of both genders weighing between 15 and $18 \mathrm{~kg}$ from the Experimental Surgery Center of the Federal University of Pernambuco.

Animals were divided into 2 groups: the study group (SG) composed of 12 dogs undergoing the new proposed continent gastrostomy technique, and the control group (CG), composed of 10 dogs undergoing the gastrostomy technique using the Janeway principle (1) as modified by Moss (6) and Webster (7).

\section{Surgical Technique for the Study Group}

A 20 -cm median incision was made in order to access the peritoneal cavity. Upon identifying the stomach and the jejunum, a jejunal segment measuring $2 \mathrm{~cm}$ in length was isolated, while preserving its vascular pedicle. The jejunal segment was then detubularized at the level of the anti-mesenteric edge and retubularized in the opposite direction through suture using separate stitches, thus creating a tube measuring $6 \mathrm{~cm}$ in length and $0.5 \mathrm{~cm}$ in diameter (Figure-1).

A longitudinal $8-\mathrm{cm}$ seromuscular incision that preserved the mucosa was made in the middle third of the stomach between the lesser and the greater curvature, separating the seromuscular layer from the gastric mucosa in the 2 directions laterally to the incision. A small opening was made in the mucosa at the incision's lower level where the lower margin of the jejunal tube was introduced and sutured to the orifice. The remainder of this tube was placed over the previously dissected gastric mucosa and then covered by the seromuscular layer constituting the antireflux valvular mechanism. The upper margin of the jejunal tube was exteriorized through the upper angle of the surgical incision (Figure-2).

\section{Surgical Technique for the Control Group}

We used the technique proposed by Webster (7), which gathers the Janeway principles (1) for the creation of a gastric tube using a linear stapler as proposed by Moss (6), and a valvular mechanism with placation stitches at the base of the tube as proposed by Spivack (1).

The gastrostomy tube was created at the level of the middle third of the stomach in the longitudinal direction. The stomach's anterior wall was then pulled by 3 Allis forceps forming a plica measuring $2 \mathrm{~cm}$ in width and $6 \mathrm{~cm}$ in length. The TLC 55 cutting linear stapler was then inserted in the stomach's wall under the forceps under traction, so that a circular tube would result after the stapling. Plication stitches were applied at the base to create the valvular system and the tube was then exteriorized and fixed to the skin through a passage between the fibers of the left rectus muscle of abdomen. At the end of the procedure, the surgical wound was closed as in the SG (Figure$3)$.

\section{Evaluation}

On the 90th postoperative day, all animals from both groups underwent tests for assessing com-

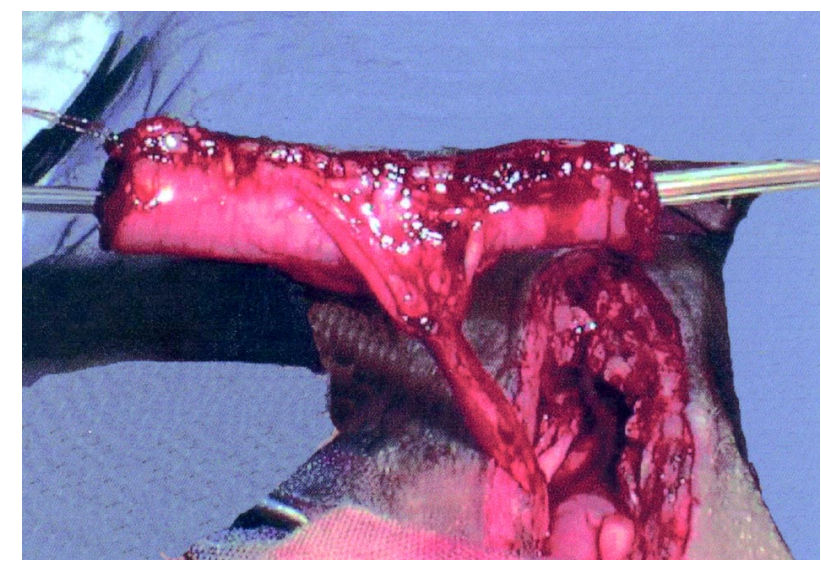

Figure 1-Re-tubularized jejunal segment before being inserted into the stomach. 


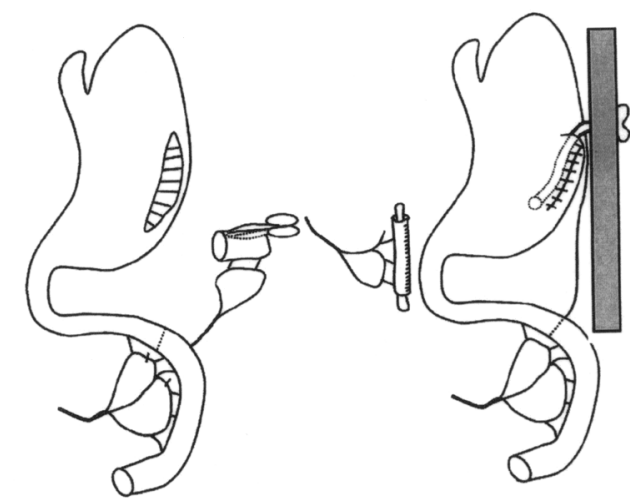

Figure 2 - Schematic drawing of surgical technique in the study group.

petency concerning leakage, initially with the live animal and then following its sacrifice.

Under general anesthesia, 2 orogastric tubes were introduced, one for infusion of saline solution with methylene blue up to a final volume of 1500 $\mathrm{mL}$, and the other for measuring the gastric tension generated by saline infusion. A laparotomy was performed for clamping the pylorus. Tensions were measured in linear $\mathrm{cm}$ of $\mathrm{H}_{2} \mathrm{O}$, in a scale where the zero point corresponded to the level of the animal's midaxillary line.

Following sacrifice, the esophagus, stomach, gastrostomy segment and first duodenal portion were removed en-bloc and placed over a flat surface. Next, as in the previous test, 2 orogastric tubes were introduced into the esophagus, this time with ligation of the extremities in order to avoid gastroesophageal reflux and duodenal emptying. A saline solution drip with methylene blue was infused up to a final volume of $1500 \mathrm{~mL}$. The tensions were checked and measured at the same scale, establishing the table's surface level as the zero point.

Macro and microscopic analyses of the gastric tubes and implanted intestinal segments were performed as well.

Results of continuous variables were expressed by their mean and standard deviation. Re-

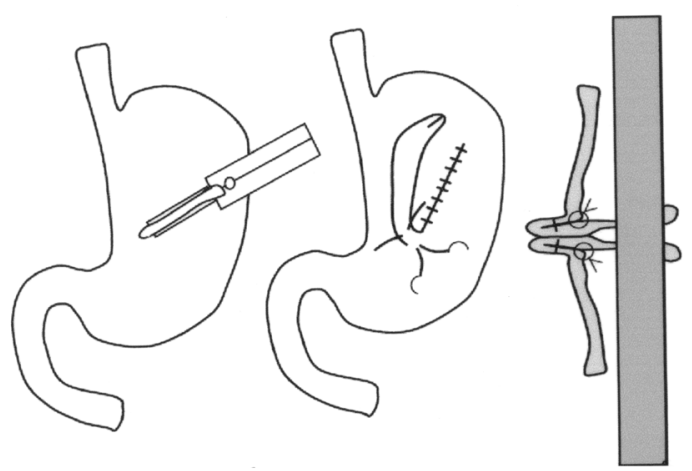

Figure 3 - Schematic drawing of surgical technique in the control group.

sults of categorical variables were expressed by their absolute and relative frequencies.

The Student's " $t$ " test for non-paired samples was used. The qui-square test was used for assessing a potential difference between frequencies. The Fisher's exact test was used in $2 \times 2$ contingency tables.

$\mathrm{P}$ value $<0.05$ was considered statistically significant.

\section{RESULTS}

\section{Study Group}

Of the 12 animals that underwent continent gastrostomy using the Monti principle, 9 were assessed for the continence test. Two animals died in the immediate post-operative period due to anesthetic accident and were replaced. One died on the 63rd day due to peritonitis and gastric perforation caused by duodenal obstruction resulting from external compression due to splenic volvulus.

On the third and fifth postoperative days, 2 animals presented dehiscence of the surgical wound that was restricted to the skin and repaired with no consequences.

The gastrostomy stomas maintained a good aspect with no signs of skin erosion at the implanta- 
tion site. All allowed gastric catheterization with a Nelaton 8F catheter without any difficulty. In 2 animals, we observed the formation of a pellicle over the stoma, which was easily removed during catheterization.

In all animals, the gastric mucosa and the jejunal segment had macroscopically normal aspects with no signs of ulceration or irritation.

Only 1 animal had leakage through the gastrostomy when the saline infusion into the stomach reached $800 \mathrm{~mL}$. The remaining animals endured a gastric volume of $1500 \mathrm{~mL}$ without leakage.

On the post-sacrifice continence test, leakage was seen in 2 animals (Table-1).

\section{Control Group}

All animals survived the experiments, however erosion of the skin surrounding the stomas was seen in 9 animals, and 5 of these presented tube retraction with closure of the gastrostomies. Six animals were re-operated upon, including 2 to correct stenosis of the gastrostomy stoma and 4 for laparotomy to reimplant the gastrostomy tubes, which had subaponeurotic retractions (Table-2). The latter were tested for gastric continence 3 months after the corrections.

When tested for gastric continence under general anesthesia, only 2 animals had leakage. On the gastric continence test performed following sacrifice, only 1 of the 10 animals did not present leakage (Table-3).

When the SG and the CG were compared regarding the leakage test under anesthesia, there was no statistically significant difference when the Fisher's test was applied $(p=1.000)$. In relation to the post-sacrifice leakage test, there was a significantly higher frequency of leakage in the $\mathrm{CG}(\mathrm{p}=$ 0.0005).

\section{Histopathological analysis}

\section{Study Group}

In this group, the gastric mucosa around the jejunal tube had normal features with no inflammatory signs. The jejunal tubes were internally covered by mucosa characterized by the presence of villosities covered by columnar epithelium with abundant goblet cells and some erosion foci. The chorion was

Table 1 - Continence analysis in the study group. The mean infused volume under anesthesia (1422 $\mathrm{mL}+1-426)$ was not different from the infused volume following sacrifice $(t=0.824, p=0.422)$.

\begin{tabular}{|c|c|c|c|c|c|c|c|}
\hline \multirow[b]{2}{*}{$\mathbf{N}$} & \multicolumn{3}{|c|}{ Under Anesthesia } & \multicolumn{3}{|c|}{ Following Sacrifice } & \multirow[b]{2}{*}{ Obs. } \\
\hline & Volume (mL) & $\begin{array}{l}\text { Tension } \\
\left(\mathrm{cm} \mathrm{H}_{2} \mathrm{O}\right)\end{array}$ & Leakage & Volume (mL) & $\begin{array}{r}\text { Tension } \\
\left(\mathrm{cm} \mathrm{H}_{2} \mathrm{O}\right)\end{array}$ & Leakage & \\
\hline 1 & 1500 & 15 & - & 1500 & 12 & - & \\
\hline 2 & & & & & & & Death \\
\hline 3 & 1500 & 10 & - & 1500 & 13 & - & \\
\hline 4 & 1500 & 17 & - & 700 & 10 & + & \\
\hline 5 & 1500 & 17 & - & 1500 & 19 & - & \\
\hline 6 & 800 & 14 & + & 400 & 8 & + & \\
\hline 7 & 1500 & 14 & - & 1500 & 14 & - & \\
\hline 8 & 1500 & 30 & - & 1500 & 30 & - & \\
\hline 9 & & & & & & & Death \\
\hline 10 & 1500 & 10 & - & 1500 & 17 & - & \\
\hline 11 & 1500 & 16 & - & 1500 & 12 & - & \\
\hline 12 & & & & & & & Death \\
\hline
\end{tabular}


Table 2 - Complications in the control group.

\begin{tabular}{|c|c|c|c|c|c|c|}
\hline $\mathbf{N}$ & $\begin{array}{c}\text { Skin } \\
\text { Erosion }\end{array}$ & $\begin{array}{c}\text { Stomal } \\
\text { Stenosis }\end{array}$ & $\begin{array}{l}\text { Gastrostomy } \\
\text { Retraction }\end{array}$ & Re-operation & $\begin{array}{c}\text { Repair of } \\
\text { Stenosis }\end{array}$ & Laparotomy \\
\hline 1 & + & - & - & - & - & - \\
\hline 2 & + & + & + & + & + & - \\
\hline 3 & - & - & - & - & - & - \\
\hline 4 & + & + & + & + & + & + \\
\hline 5 & + & - & - & - & - & - \\
\hline 6 & + & - & - & - & - & - \\
\hline 7 & + & + & + & + & + & + \\
\hline 8 & + & + & - & + & + & - \\
\hline 9 & + & + & + & + & + & + \\
\hline 10 & + & + & + & + & + & + \\
\hline
\end{tabular}

Table 3 - Continence test in the control group. Mean volume of saline solution infused under anesthesia $(1450 \mathrm{~mL}+/-$ 105) was significantly higher $(t=5.537, p<0.001)$ than the volume infused following sacrifice $(695+/-396 \mathrm{~mL})$.

\begin{tabular}{lcccccc}
\hline $\mathbf{N}$ & $\begin{array}{c}\text { Volume } \\
(\mathrm{mL})\end{array}$ & $\begin{array}{c}\text { Under Anesthesia } \\
\text { Tension } \\
\left(\mathrm{cm} \mathrm{H}_{2} \mathrm{O}\right)\end{array}$ & Leakage & $\begin{array}{c}\text { Volume } \\
(\mathrm{mL})\end{array}$ & $\begin{array}{c}\text { Following Sacrifice } \\
\text { Tension } \\
\left(\mathrm{cm} \mathrm{H}_{2} \mathrm{O}\right)\end{array}$ & Leakage \\
\hline 1 & 1.250 & 12 & + & 350 & 6 & + \\
2 & 1.250 & 10 & + & 750 & 8 & + \\
3 & 1.500 & 9 & - & 750 & 10 & + \\
4 & 1.500 & 13 & - & 600 & 10 & + \\
5 & 1.500 & 15 & - & 1250 & 9 & + \\
6 & 1.500 & 13 & - & 1500 & 8 & + \\
7 & 1.500 & 13 & - & 350 & 4 & + \\
8 & 1.500 & 15 & - & 500 & 5 & + \\
9 & 1.500 & 13 & - & 600 & 6 & + \\
10 & 1.500 & 10 & & 300 & 3 & + \\
\hline
\end{tabular}

enlarged due to the presence of moderate mononuclear inflammatory infiltrate.

Around the anastomosis site between the skin and the jejunal tube, we observed mild inflammatory infiltrate, predominantly mononuclear, with no signs of ulceration. These findings were common to all the examined specimens.

\section{Control Group}

Skin ulceration around the gastrostomy tube stomas was constant, with a presence of reparative changes in the gastric mucosa at this level. The tube mucosa had typical features of the mucosa found in the gastric body where parietal and principal cells were identified. In the chorion, there was mono- and polymorphonuclear infiltrate, less intense than the one detected in the SG.

\section{COMMENTS}

Gastrostomy remains the best method for giving nutrients to a considerable amount of patients who, 
due to different causes, are unable to use the oral route for this purpose.

The rationale for using the Monti principle to construct a continent gastrostomy was based on the encouraging results obtained by different authors in the performance of vesicostomies and cecostomies that showed to be continent and easy to perform (811). The surgical technique does not present major difficulties and can be performed by anyone who is familiar with intestinal anastomoses.

The SG was the first to be performed, thus it was more exposed to the learning curve, especially concerning the anesthesia, which, due to technical reasons, resulted in the death of 2 animals.

The repetition of continence tests following sacrifice was designed to test the competence of the valvular mechanism without influence of the gastroesophageal reflux, a variable factor that could interfere with the results. The use of methylene blue in the test's saline solution aimed to improve the visualization for identifying gastric leakage. The standardized maximum volume of $1500 \mathrm{~mL}$ of saline solution infused into the stomach was established after assessments performed on the pilot animal where the infused volume did not result in leakage.

When comparing both groups in relation to surgical technique, we observed that the technique employed in the control group with the aid of the linear stapler while creating the gastric tube made the surgical procedure easier, reducing the surgical time. However, it did not seem to prevent the gastric leakage observed in the post-sacrifice test, despite the appliance of plication stitches at its base in compliance with the anti-reflux Spivack technique (1). In the $\mathrm{CG}$, the gastrostomy tube was exteriorized though the rectus muscle of the abdomen, which confers an additional valvular system. We believe that this explains the different results observed between in vivo and post-sacrifice continence tests. The statistical analysis of leakage frequency following sacrifice gives mathematical support to the biological observation. Moreover, when compared to the $\mathrm{CG}$, the highest volume of saline solution infused in the animals' stomach in the SG gives additional support to the efficiency of the valvular system projected for gastrostomy continence.
The SG showed to be more effective concerning the control of gastric leakage, despite the gastrostomy tube being exteriorized at the level of the linea alba; that is, without muscular influence. This allows us to suggest that the observed continence was dependent exclusively on the submucous valvular mechanism. Another important fact is that in the SG, the gastrostomy tube was created with a jejunal segment whose mucosa does not have acid secretion, while in the $\mathrm{CG}$ a gastric tube was used, consequently creating an acid-secreting mucosa, which, in association with gastric leakage, may have contributed to the development of erosions and dehiscences around the gastrostomy stomas.

Similarly to the Janeway technique and also to other approaches that use part of the stomach as a gastrostomy device, another advantage of the gastrostomy with the jejunal tube using the Monti principle is that this technique is difficult to apply to patients who undergo partial gastrectomy, while in the proposed technique, the jejunal tube added to the stomach can be applied to any segment $(1,12)$.

The elaboration of catheterization tubes through transverse re-tubularization of small intestinal segments has provided its use in several segments of the digestive tract, allowing the performance of several functions through continent cecostomy and sigmoidostomy for antegrade intestinal enema used for treating neurogenic constipation (8-11). Other uses can be tested in the future, such as continent jejunostomy for feeding gastrectomy patients where a gastrostomy is not possible.

At the present moment, 14 patients have undergone continent gastrostomy according to this technique with quite satisfactory results.

\section{REFERENCES}

1. Partipilo AV: Surgical Technique and Principles of Operative Surgery. Philadelphia, Lea \& Febiger. 1949, pp. 245-56.

2. Osborne RO, Toffler RB: Gastrostomy tube prolapse. Am J Gastroenterol. 1973; 60: 602-6.

3. Sherman ML, Cosgrove MJ, Dennis JM: Gastrostomy tube migration. Am Surg. 1973; 39: 122-3.

4. Connar RG, Sealy WC: Gastrostomy and its complication. Ann Surg 1956; 143: 245-50. 
5. Monti PR, Lara RC, Dutra MA, de Carvalho JR: New techniques for construction of efferent conduits based on the Mitrofanoff princple. Urolology. 1997; 49: 11215.

6. Moss G: A simple technique for permanent gastrostomy. Surgery. 1972; 71: 369-70.

7. Webster MW Jr, Carey LC, Ravitch MM: The permanent gastrostomy: use of the gastrointestinal anastomotic stapler. Arch Surg. 1975; 110: 658-60.

8. Gerharz EW, Tassadaq T, Pickard RS, Shah PJ, Woodhouse CR, Ransley PG: Transverse re-tubularized ileum: early clinical experience with a new second line Mitrofanoff tube. J Urol. 1998; 159: 525-8.
9. Gosalbez R, Wei D, Gousse A, Castellan M, Labbie A: Refashioned short bowel segments for the construction of catheterizable channels (the Monti procedure): early clinical experience. J Urol. 1998; 160: 1099-102.

10. Castellan MA, Gosalbez R Jr, Labbie A, Monti PR: Clinical applications of the Monti procedure as a continent catheterizable stoma. Urology. 1999; 54: 1526.

11. Yerkes EB, Rink RC, Cain MP, Casale AJ: Use of a Monti channel for administration of antegrade continence enemas. J Urol. 2002; 168: 1883-5.

12. Bianchi A, Pearse B: The non-refluxing gastrostomy: an evolution. Pediatric Surg Int. 1997; 12: 494-6.

Received: October 17, 2004

Accepted after revision: January 3, 2005

\section{Correspondence address:}

Dr. Luiz Alberto P. de Araújo

Rua Edson Álvares, 211 / 601, Casa Forte

Recife, PE, 52061-450, Brazil

E-mail:1uizal12@terra.com.br 